\title{
Correction to: Liquid Crystal-Based Surface Plasmon Resonance Biosensor
}

\author{
Ali Vahedi ${ }^{1,2} \cdot$ Mohammad Kouhi ${ }^{1,2}$ \\ Published online: 26 October 2019 \\ (C) Springer Science+Business Media, LLC, part of Springer Nature 2019
}

\section{Correction to: Plasmonics \\ https://doi.org/10.1007/s11468-019-01009-5}

The article Liquid Crystal-Based Surface Plasmon Resonance Biosensor, written by Ali Vahedi and Mohammad Kouhi, was originally published electronically on the publisher's internet portal (currently SpringerLink) on August 10, 2019 with open access. With the author(s)' decision to step back from Open Choice, the copyright of the article changed on September 10, 2019 to (C) Springer Science+Business Media, LLC, part of Springer Nature 2019 and the article is forthwith distributed under the terms of copyright.

Publisher's Note Springer Nature remains neutral with regard to jurisdictional claims in published maps and institutional affiliations.

The online version of the original article can be found at https://doi.org/ 10.1007/s11468-019-01009-5

Ali Vahedi

vahedi@iaut.ac.ir

1 Department of Physics, Tabriz Branch, Islamic Azad University, Tabriz, Iran

2 Biophotonic Research Center, Tabriz Branch, Islamic Azad University, Tabriz, Iran 